\title{
Erratum to: Effects of eccentric exercise on systemic concentrations of pro- and anti-inflammatory cytokines and prostaglandin (E2): comparison between young and postmenopausal women
}

\author{
Miguel Soares Conceição • Cleiton Augusto Libardi • Felipe Romano Damas Nogueira • \\ Valéria Bonganha · Arthur Fernandes Gáspari - Mara Patrícia Traina Chacon-Mikahil • \\ Cláudia Regina Cavaglieri • Vera Aparecida Madruga
}

Published online: 22 May 2012

(C) Springer-Verlag 2012

\section{Erratum to: Eur J Appl Physiol}

DOI 10.1007/s00421-011-2292-6

The original publication of the article includes some errors which should be corrected as given below.

In "Methods", the IL-10 sensitivity is provided for both "30.9 $\mathrm{pg} / \mathrm{mL}$ " and " $0.5 \mathrm{pg} / \mathrm{mL}$ " beneath the subheading "CK activity, cytokines, $\mathrm{PGE}_{2}$ and hormone". The correct value should read " $0.5 \mathrm{pg} / \mathrm{mL}$ ".

In Tables 3 and 4 in "Results", the double asterisks are incorrectly inserted both in tables and in the footnotes denoting value “**p $<0.01$ ”. It should read as single asterisk in both cases "* $p<0.05$ ".

The online version of the original article can be found under doi:10.1007/s00421-011-2292-6.

M. S. Conceição $(\bowtie)$ · C. A. Libardi · F. R. D. Nogueira •

V. Bonganha · A. F. Gáspari · M. P. T. Chacon-Mikahil ·

C. R. Cavaglieri · V. A. Madruga

Laboratory of Exercise Physiology, (FISEX),

Faculty of Physical Education (FEF),

State University of Campinas (UNICAMP), Campinas, Brazil

e-mail: conceicao.migue10106@gmail.com 